\title{
Respostas morfogênicas e estruturais de dosséis de espécies de Braquiária à intensidade de desfolhação
}

\author{
Márcio André Stefanelli Lara(1) e Carlos Guilherme Silveira Pedreira(2)
}

(1)Universidade Federal de Lavras, Departamento de Zootecnia, Caixa postal 3037, CEP 37200-000, Lavras, MG. E-mail: marcioaslara@gmail.com
(2)Escola Superior de Agricultura Luiz de Queiroz, Avenida Pádua Dias № 11, CEP 13418-970 Piracicaba, SP. E-mail:cgspedre@esalq.usp.br

Resumo - O objetivo deste trabalho foi avaliar as respostas morfogênicas e estruturais de duas espécies e cinco cultivares de braquiária a intensidades de desfolhação. As cultivares Marandu, Xaraés, Arapoty, Capiporã (Urochloa brizantha) e Basilisk (U. Decumbens) foram desfolhadas mecanicamente a 15 e 7,5 cm de altura, durante o verão e o inverno. Utilizaram-se unidades experimentais de $9 \times 4 \mathrm{~m}$, irrigadas e adubadas com $220 \mathrm{~kg} \mathrm{ha}^{-1}$ por ano de $\mathrm{N}$ e $\mathrm{K}_{2} \mathrm{O}$. As características morfogênicas avaliadas foram: filocrono e senescência, duração de vida e taxas de aparecimento e alongamento de folhas. As características estruturais foram: número de folhas vivas por perfilho, comprimento final das folhas expandidas e de colmos, relação senescência/ crescimento e densidade populacional de perfilhos. Variações nas condições meteorológicas, em cada estação, promoveram aumentos nas taxas de aparecimento e alongamento, diminuição do filocrono e duração de vida das folhas. As características estruturais mais responsivas ao gradiente promovido pelas alturas de corte foram o comprimento final de folhas expandidas e a densidade populacional de perfilhos. A altura de corte mais baixa exerceu maior impacto na dinâmica de crescimento do que na senescência, em perfilhos individuais. As cultivares Xaraés e Capiporã foram as mais produtivas, em razão das maiores taxas de alongamento foliar e maior densidade populacional de perfilhos.

Termos para indexação: Brachiaria, Urochloa, fluxo de tecidos, manejo da desfolhação, morfogênese, senescência.

\section{Structural and morphogenetic responses of swards of Brachiaria species to defoliation intensity}

\begin{abstract}
The objective of this work was to evaluate structural and morphogenetic responses of two species and five cultivars of brachiaria to defoliation intensities. The cultivars Marandu, Xaraés, Arapoty, Capiporã (Urochloa brizantha), and Basilisk (U. decumbens) were mechanically defoliated at 15 and $7.5 \mathrm{~cm}$, in mid-summer and mid-winter. The experimental units ( $9 \times 4 \mathrm{~m}$ plots) were irrigated and fertilized with $220 \mathrm{~kg} \mathrm{ha}^{-1}$ per year of $\mathrm{N}$ and $\mathrm{K}_{2} \mathrm{O}$. Morphogenetic characteristics measured were: phyllochron, leaf senescence and life span, and leaf appearance and elongation rate. The structural characteristics evaluated were: number of leaves per tiller, final leaf length of fully expanded leaves, stems length, senescence/growth ratio, and tiller density. Variations in meteorological conditions of each season promoted increasing of the appearance rates and leaf elongation, and decreasing of the phyllochron and leaf life span. The structural features most responsive to the gradient promoted by harvesting heights were the final leaf length of expanded leaves and tiller density. The lower harvest height had the greatest impact on growth dynamics in comparison to senescence, in individual tillers. The cultivars Xaraés and Capiporã were more productive due to higher leaf elongation rates and higher tiller density.
\end{abstract}

Index terms: Brachiaria, Urochloa, tissue flows, defoliation management, morphogenesis, senescence.

\section{Introdução}

Muitos processos ligados ao desenvolvimento vegetativo das plantas ganham ou perdem intensidade à medida que elas crescem. A taxa de aparecimento de folhas (TAPF) diminui, ao passo que o tempo de alongamento foliar e o comprimento da lâmina foliar aumentam, e essas mudanças são concomitantes ao alongamento da bainha foliar. Essas modificações na morfologia do perfilho também ocorrem em taxas variáveis, de acordo com a época do ano, com a disponibilidade de fatores de crescimento-principalmente temperatura enitrogênioe com as próprias características de desenvolvimento

Pesq. agropec. bras., Brasília, v.46, n.7, p.760-767, jul. 2011 
da espécie forrageira considerada (Martuscello et al., 2005). Mudanças no manejo das plantas influenciam o número de células em divisão e a capacidade de alongamento celular, o que acelera ou retarda a taxa de alongamento foliar (TALF) e aumenta ou diminui o comprimento final das folhas (CFF); esses fatores modificam o ritmo morfogênico das plantas (Gomide et al., 2006).

Segundo Duru \& Ducrocq (2000), variações na TAPF estão relacionadas ao comprimento do pseudocolmo, ou seja, à capacidade da planta de promover variações no alongamento das bainhas foliares. Essa relação pode ser o fator fundamental nas respostas da TAPF ao suprimento de $\mathrm{N}$ ou, ainda, pode atuar da mesma forma quando são impostas às pastagens, intensidades contrastantes de desfolhação. As respostas das plantas pastejadas variam em função do regime de desfolhação (intensidade e frequência), época do ano e do estádio fenológico no momento da desfolhação. A compreensão dos efeitos do pastejo sobre as plantas forrageiras requer o conhecimento e a análise das modificações morfológicas e fisiológicas, pois, nestas condições, a morfogênese tem papel importante na elucidação dos mecanismos adaptativos, desenvolvidos em resposta à desfolhação, e de suas consequências sobre a morfologia e estrutura de perfilhos (Pedreira et al., 2007; Silva \& Nascimento Júnior, 2007).

Diversos autores alertam para a necessidade primária do conhecimento das respostas morfofisiológicas da espécie forrageira utilizada para que a aceleração no ritmo morfogênico seja explorada de forma correta e os ganhos em produtividade sejam duradouros e efetivos (Lemaire \& Agnusdei, 2000; Suplick et al., 2002; Alexandrino et al., 2004; Rezende et al., 2008). $\mathrm{O}$ manejo equivocado de forragens pode causar prejuízos à estrutura do dossel além de elevadas perdas por senescência, com efeitos negativos sobre o desempenho animal e a perenidade das pastagens.

O objetivo deste trabalho foi avaliar as respostas morfogênicas e estruturais de duas espécies e cinco cultivares de braquiária a intensidades de desfolhação.

\section{Material e Métodos}

$\mathrm{O}$ experimento foi conduzido em área experimental do Departamento de Zootecnia, da Escola Superior de Agricultura Luiz de Queiroz, da Universidade de São Paulo, no Município de Piracicaba, SP, a $22^{\circ} 42^{\prime}$ S, $47^{\circ} 30^{\prime} \mathrm{W}$ e altitude de $580 \mathrm{~m}$, com precipitação anual de $1.002 \mathrm{~mm}$ e média de temperatura de $23,6^{\circ} \mathrm{C}$ no verão (outubro a março) e $13,3^{\circ} \mathrm{C}$ no inverno (abril a setembro).

Foram estudadas as cultivares Marandu, Xaraés, Arapoty e Capiporã de Urochloa brizantha (Syn. Brachiaria brizantha), e a cultivar Basilisk de $U$. decumbens (Syn. B. decumbens), estabelecidas no verão de 2004-2005. Empregou-se o delineamento experimental de blocos ao acaso, com parcelas subdivididas e quatro repetições. As cultivares foram alocadas às parcelas $(4 \mathrm{x} 9 \mathrm{~m})$, que foram subdivididas longitudinalmente em duas metades. Cada metade foi submetida a uma altura de corte específica: 15 ou $7,5 \mathrm{~cm}$. Durante o período experimental, a forragem das parcelas foi cortada com motossegadora de barra. Para avaliar o efeito da estação do ano sobre as características morfogênicas e estruturais das forrageiras. As avaliações de morfogênese ocorreram em dois ciclos de rebrotação distintos, representativos do verão (de 7 de dezembro 2007 a 4 de janeiro 2008, total 28 dias) e do inverno (de 7 de junho a 19 de julho de 2008, total 42 dias) agrostológicos.

O manejo da irrigação foi baseado no monitoramento das condições hídricas do solo, por meio de quatro tensiômetros instalados na área experimental a $30 \mathrm{~cm}$ de profundidade. Sempre que os tensiômetros registravam valores médios de potencial hídrico no solo entre $-0,30$ e -0,40 kPa, procedia-se à irrigação. A irrigação também foi realizada após cada adubação, sempre após os cortes, para maximizar a eficiência do adubo aplicado.

O solo da área experimental é classificado como Nitossolo Vermelho eutroférrico com horizonte (A) moderado e textura argilosa a muito argilosa (Santos et al., 2006). As características químicas na camada de 0-20 cm, avaliadas em outubro de 2007, foram: $\mathrm{pH}$ em $\mathrm{H}_{2} \mathrm{O}, 5,9$; matéria orgânica, $42 \mathrm{~g} \mathrm{dm}^{-3}$; $\mathrm{P}$ (resina), $20 \mathrm{mg} \mathrm{dm}^{-3}$; K, 4,0 $\mathrm{mmol}_{\mathrm{c}} \mathrm{dm}^{-3}$; Ca, $54 \mathrm{mmol}_{\mathrm{c}} \mathrm{dm}^{-3}$; $\mathrm{Mg}, 16 \mathrm{mmol}_{\mathrm{c}} \mathrm{dm}^{-3} ; \mathrm{H}+\mathrm{Al}, 28 \mathrm{mmol}_{\mathrm{c}} \mathrm{dm}^{-3}$; soma de bases, $74 \mathrm{mmol}_{\mathrm{c}} \mathrm{dm}^{-3}$; T, $102 \mathrm{mmol}_{\mathrm{c}} \mathrm{dm}^{-3}$; e saturação por bases, $73 \%$. Não foi necessário fazer correções para as gramíneas forrageiras utilizadas no experimento. As adubações foram realizadas manualmente, logo após os cortes, com $20 \mathrm{~kg} \mathrm{ha}^{-1}$ de $\mathrm{N}$ e de $\mathrm{K}_{2} \mathrm{O}$ por ciclo de rebrotação, o que totalizou $220 \mathrm{~kg} \mathrm{ha}^{-1}$ por ano de $\mathrm{N}$ e de $\mathrm{K}_{2} \mathrm{O}$, na forma de sulfato de amônio e de cloreto de potássio, respectivamente. 
Para a avaliação das características morfogênicas e estruturais, foi escolhido um ponto representativo da condição média das subparcelas. Nesses locais, foram selecionados cinco perfilhos de diferentes plantas, que foram identificados e numerados. Em decorrência da acelerada renovação de tecidos no verão, os perfilhos foram monitorados duas vezes por semana e, no inverno, o monitoramento ocorreu semanalmente. Nos procedimentos de avaliação, as folhas foram numeradas e classificadas como intactas, desfolhadas, senescentes e mortas. As folhas intactas e as desfolhadas foram classificadas como inteiramente expandidas, com lígula visível ou em expansão, sem lígula visível. A classificação como senescente baseouse na ocorrência de alguma porção da lâmina foliar com início do processo de senescência. Folhas em que mais de $50 \%$ do comprimento do limbo foliar estivessem comprometidos pela senescência foram consideradas mortas.

O comprimento do limbo foliar foi medido de acordo com o estádio de desenvolvimento das folhas. Para folhas expandidas, foi considerado o comprimento da ponta da folha até a lígula. Para folhas em expansão, o procedimento foi semelhante, exceto o referencial de medida, que passou a ser a lígula da folha mais jovem completamente expandida (Duru \& Ducrocq, 2000). Quanto às folhas em senescência, foi considerado o comprimento da lâmina foliar, a partir da lígula até o ponto onde o processo de senescência tinha avançado. O comprimento do colmo (colmo + bainhas) foi medido como sendo a distância entre o nível do solo e a lígula da folha mais jovem completamente expandida.

A densidade populacional de perfilhos (DPP) foi medida em três períodos, dentro de cada rebrotação início, meio e final -, por meio de contagens do número total de perfilhos contidos no interior de dois retângulos de $(0,2 \times 0,5 \mathrm{~m})$ por unidade experimental. Os perfilhos foram classificados em basais ou aéreos.

A partir dessas informações, foram calculadas as seguintes variáveis morfogênicas e estruturais: taxa de aparecimento de folhas (TAPF, folhas por perfilho por dia), divisão do número médio de folhas surgidas por perfilho, pelo número de dias do intervalo de avaliação; filocrono (Filo, dias por folha), inverso da taxa de aparecimento de folhas; duração de vida das folhas (DVF, dias), intervalo do aparecimento da folha até sua total senescência, estimada pela equação $\mathrm{DVF}=\mathrm{NFV} \times$ Filo (Lemaire \& Chapman, 1996), em que NFV é o número de folhas vivas por perfilho; taxa de alongamento de folhas (TALF, cm por perfilho por dia), é a divisão da variação média do comprimento das lâminas foliares em expansão por perfilho, pelo número de dias do intervalo de avaliação; taxa de senescência de folhas (TSF, cm por perfilho por dia), é a divisão da variação média do comprimento da porção senescente da lâmina foliar por perfilho, pelo número de dias do intervalo de avaliações; NFV, obtido a partir do número médio de folhas em expansão, expandidas e em senescência por perfilho, excluíndo-se as folhas com mais de $50 \%$ do limbo foliar em processo de senescência; comprimento final das folhas expandidas (CFF, cm), comprimento final das lâminas foliares, tendo sido consideradas apenas as não desfolhadas; comprimento médio de colmo + pseudocolmo $(\mathrm{CC}, \mathrm{cm})$, distância entre a lígula da última folha expandida em relação ao solo ou à inserção no perfilho de origem, no caso de perfilhos basais ou aéreos, respectivamente; relação senescência/crescimento (relação $\mathrm{S} / \mathrm{C}$ ), é a razão entre a taxa de senescência $(\mathrm{cm}$ por perfilho por dia) e a taxa de crescimento ( $\mathrm{cm}$ por perfilho por dia). Densidade populacional de perfilhos (DPP, perfilhos $\mathrm{m}^{-2}$ ), é o número de perfilhos por unidade de área.

Os dados foram analisados por meio de modelos mistos, com o procedimento mixed do SAS (SAS Institute, 2001). Os efeitos de cultivar, altura de corte e estação do ano foram considerados como efeitos fixos. Os blocos e suas interações com as demais fontes de variação foram considerados efeitos aleatórios (Littell et al., 2006). As médias dos tratamentos foram estimadas por meio do LSMeans, e a comparação entre as médias foi realizada por meio da probabilidade da diferença (PDIFF) ajustada para o teste de Tukey, a 5\% probabilidade.

\section{Resultados e Discussão}

A TAPF sofreu efeito da interação cultivar $x$ estação, tendo sido cerca de duas vezes maior no verão agrostológico, para todas as cultivares, em comparação ao inverno (Tabela 1). As cultivares Arapoty, Basilisk e Capiporã tiveram as maiores TAPF no verão. No inverno, as variações na TAPF entre as cultivares foram menores.

A TALF sofreu efeito da altura de corte, da estação e da cultivar. À altura de $7,5 \mathrm{~cm}$, a TALF foi de $1,28 \mathrm{~cm}$ por perfilho por dia, enquanto à altura de $15 \mathrm{~cm}$, a TALF 
foi de 1,09 $\mathrm{cm}$ por perfilho por dia, aproximadamente 15\% menor nessa altura. Segundo Davies (1974), a TALF é pouco afetada pela desfolhação, e a redução na taxa de alongamento de novas folhas seria afetada em 15 a $20 \%$, quando todas as folhas do perfilho são removidas. De forma análoga, a redução de $50 \%$ na altura de corte, no presente trabalho, removeu grande quantidade de folhas e afetou a TALF. Barbosa et al. (2002) não notaram efeito de dois resíduos $(2,3 \mathrm{e}$ 3,6 $\mathrm{Mg} \mathrm{ha}^{-1}$ de MS), no pós-pastejo, sobre a TALF, em pastagens de capim-tanzânia, provavelmente em razão da restrição hídrica ou da quantidade de folhas remanescentes na massa de forragem.

A TALF foi cerca de $30 \%$ maior no verão, com valores que alcançaram $1,39 \mathrm{~cm}$ por perfilho por dia. No inverno, a TALF média foi de $0,99 \mathrm{~cm}$ por perfilho por dia. Outro fator influente na dinâmica do aparecimento e alongamento foliar é a genética dos materiais usados. As cultivares Xaraés e Capiporã tiveram as maiores TALF $(1,45 \mathrm{e} 1,38 \mathrm{~cm}$ por perfilho por dia, respectivamente), e esta é uma característica de genótipos produtivos, mesmo quando estão sob diferentes condições de manejo. Os genótipos Basilisk e Marandu apresentaram as menores TALF $(0,91$ e $1,01 \mathrm{~cm}$ por perfilho por dia, respectivamente). A TALF do genótipo Arapoty foi intermediária, de $1,20 \mathrm{~cm}$ por perfilho por dia. Segundo Suplick et al. (2002), a temperatura é um fator ambiental controlador da TAPF em gramíneas, que regula as relações lineares entre o número de folhas surgidas e a temperatura acumulada, ou seja, é um fator que não pode ser completamente regulado pela ação do manejador. $\mathrm{O}$ alongamento foliar é resultante da produção de células, a partir da zona de crescimento das folhas-zonas de divisão, alongamento e maturação celular -, onde os suportes nutricional e hídrico atuam fortemente. No presente trabalho, o controle da adubação e da irrigação proporcionou a TALF como resposta direta do manejo e estação do ano para cada genótipo.

A altura de corte de $7,5 \mathrm{~cm}$ foi responsável pela maior TALF nos perfilhos. Os valores de filocrono sofreram efeito da altura de corte e da estação, em que intervalos maiores no aparecimento de folhas ocorreram para a altura de $15 \mathrm{~cm}$, em média 18 dias por folha por perfilho. Intervalos menores entre o aparecimento de duas folhas ocorreram com a redução da altura de corte e foram equivalentes a 16,2 dias por folha por perfilho.

O filocrono varia conforme a espécie forrageira, mas, para um mesmo genótipo, o filocrono varia com a estação do ano, em decorrência das condições de luz, temperatura e umidade no solo (Paciullo et al., 2003). O maior período necessário para o aparecimento de duas folhas consecutivas, durante o inverno, evidencia a situação desfavorável das plantas ao serem submetidas à baixa precipitação pluvial e à diminuição da temperatura e do fotoperíodo. No inverno, os genótipos apresentaram maior filocrono, em média 22,4 dias por folha por perfilho, o que correspondeu ao dobro de filocrono no verão, em média 11,6 dias por folha por perfilho; esses dados corroboram os resultados encontrados em capim-marandu (Pereira, 2009; Casagrande et al., 2010). Sbrissia \& Silva (2008) comentam, ainda, que a TAPF e o filocrono dependem da TALF e da distância que a lâmina foliar percorre desde sua emissão até sua visualização acima do cartucho de folhas mais velhas. Dosséis colhidos a $7,5 \mathrm{~cm}$ apresentam colmos menores e, portanto o aparecimento completo das folhas ocorre mais rapidamente do que em dosséis colhidos mais altos, nos quais o tempo necessário para o aparecimento da lígula é maior.

Tabela 1. Taxa de aparecimento de folhas (TAPF) e duração de vida de folhas (DVF) de cinco cultivares de Urochloa spp., no verão e inverno agrostológicos ${ }^{(1)}$.

\begin{tabular}{|c|c|c|c|c|c|c|}
\hline Estação & Arapoty & Basilisk & Capiporã & Marandu & Xaraés & Média \\
\hline & \multicolumn{6}{|c|}{ TAPF (Folhas por perfilho por dia) } \\
\hline Verão & $0,108 \pm 0,0029 \mathrm{Aa}$ & $0,103 \pm 0,0018 \mathrm{ABa}$ & $0,091 \pm 0,0059 \mathrm{ABa}$ & $0,086 \pm 0,0052 \mathrm{BCa}$ & $0,066 \pm 0,0034 \mathrm{Ca}$ & $0,091 \pm 0,0018$ \\
\hline Inverno & $0,058 \pm 0,0029 \mathrm{Ab}$ & $0,041 \pm 0,0018 \mathrm{Bb}$ & $0,050 \pm 0,0059 \mathrm{ABb}$ & $0,042 \pm 0,0052 \mathrm{ABb}$ & $0,038 \pm 0,0034 \mathrm{Bb}$ & $0,046 \pm 0,0018$ \\
\hline \multirow[t]{2}{*}{ Média } & $0,083 \pm 0,0021$ & $0,072 \pm 0,0013$ & $0,070 \pm 0,0042$ & $0,064 \pm 0,0037$ & $0,052 \pm 0,0024$ & - \\
\hline & \multicolumn{6}{|c|}{ DVF (Dias por folha) } \\
\hline Verão & $46 \pm 4,36 \mathrm{Bb}$ & $50 \pm 4,36 \mathrm{ABb}$ & $56 \pm 4,36 \mathrm{ABb}$ & $66 \pm 4,36 \mathrm{Ab}$ & $64 \pm 4,36 \mathrm{Ab}$ & $57 \pm 1,98$ \\
\hline Inverno & $104 \pm 4,36 \mathrm{Ba}$ & $128 \pm 4,36 \mathrm{Aa}$ & $102 \pm 4,36 \mathrm{Ba}$ & $123 \pm 4,36 \mathrm{Aa}$ & $125 \pm 4,36 \mathrm{Aa}$ & $117 \pm 1,98$ \\
\hline Média & $75,5 \pm 3,37$ & $89,4 \pm 3,37$ & $79,8 \pm 3,37$ & $94,9 \pm 3,37$ & $95,1 \pm 3,37$ & - \\
\hline
\end{tabular}

${ }^{(1)}$ Médias \pm erro-padrão seguidas de letras iguais, minúsculas nas colunas e maiúsculas nas linhas, não diferem pelo teste de Tukey, a $5 \%$ de probabilidade. 
A DVF é uma característica importante na determinação do fluxo de tecidos em perfilhos individuais e variou em razão da altura de corte e da interação cultivar $\mathrm{x}$ estação (Tabela 1). Dosséis dos cinco genótipos colhidos a $15 \mathrm{~cm}$ de altura apresentaram maior DVF - cerca de 90 dias -, enquanto os dosséis colhidos a 7,5 $\mathrm{cm}$ de altura apresentaram menor DVF, em média 83 dias. Essa redução na longevidade é resultado da maior dinâmica de renovação de tecidos e perfilhos, nessas condições.

Segundo Navas et al. (2003), a curta DVF está associada a elevadas taxas de crescimento e fixação de carbono, enquanto folhas longevas contribuem para a conservação de nutrientes na planta, o que indica que as plantas utilizam a estratégia de absorção de nutrientes na época de elevada disponibilidade de fatores de crescimento e que, em épocas de limitação desses fatores, a estratégia utilizada seria basicamente a de conservação dos nutrientes já assimilados.

A taxa de senescência foliar (TSF) sofreu efeito da interação altura x estação. Os maiores valores de TALF e os menores de DVF, nas parcelas colhidas a 7,5 cm de altura, indicavam que as taxas de senescência seriam maiores nessa intensidade de desfolha, em consequência da aceleração dos processos de crescimento. No entanto, a senescência desses perfilhos no verão foi menor que a senescência de pastos colhidos a $15 \mathrm{~cm}$ de altura (Tabela 2). Essa resposta mostra a importância da estrutura do resíduo deixado após a colheita e como as estratégias de desfolhação interferem na idade média dos perfilhos nos pastos. Pastos colhidos mais baixos apresentam renovação maior de perfilhos (Santos et al., 2011); além disso, com a remoção da maior parte das folhas, aumenta a utilização da forragem produzida. Pastos com resíduos altos apresentam maiores taxas de senescência, pela presença de folhas velhas na base desses dosséis, que não são colhidas pela máquina e que estão presentes nas leituras do fluxo de tecidos. Casagrande et al. (2010) relataram que as variáveis ambientais exercem maior influência sobre as características morfogênicas, em comparação a ações de manejo, o que foi corroborado pelos dados do presente estudo, em que as diferenças observadas entre as taxas de senescência de folhas, no inverno, parecem estar ligadas mais à disponibilidade de luz e temperatura do que diretamente ao manejo (Tabela 2).

O NFV sofreu efeito da interação entre altura de corte $\mathrm{x}$ genótipo. Apenas as cultivares Basilisk e Marandu tiveram NFV diferentes entre as alturas de corte, sendo que, nas subparcelas cortadas a $15 \mathrm{~cm}$ de altura, elas tinham menos folhas vivas por perfilho (Tabela 3). Dessa forma, dosséis cortados mais rentes ao solo tiveram maior NFV, em comparação aos dosséis colhidos mais altos.

O comprimento final de folhas expandidas (CFF) sofreu efeito da altura de corte e da interação genótipo x estação. Nas subparcelas cortadas a $15 \mathrm{~cm}$, o CFF foi de $16,2 \mathrm{~cm}$. Nas subparcelas cortadas a $7,5 \mathrm{~cm}$, o CFF foi menor e correspondeu a $14,1 \mathrm{~cm}$. No verão agrostológico, o CFF foi sempre maior para todos os genótipos, em comparação ao do inverno. A cultivar Capiporã destacou-se por ter as folhas expandidas mais longas, tendo superado os $25 \mathrm{~cm}$ de comprimento, no verão (Tabela 4). Apesar de o período de crescimento ser maior no inverno, as condições climáticas limitaram a expansão das folhas na maior parte das cultivares; no entanto, a cultivar Capiporã continuou com as maiores folhas, mesmo nessa estação, o que contribuiu para a sua elevada produção de forragem.

Tabela 2. Taxa de senescência foliar ( $\mathrm{cm}$ por perfilho por dia) em pastos de Urochloa spp., sob duas alturas de corte, no verão e inverno agrostológico ${ }^{(1)}$.

\begin{tabular}{lccc}
\hline Altura de corte & Verão & Inverno & Média \\
\hline $15 \mathrm{~cm}$ & $0,108 \pm 0,010 \mathrm{Aa}$ & $0,036 \pm 0,006 \mathrm{Ba}$ & $0,072 \pm 0,006$ \\
$7,5 \mathrm{~cm}$ & $0,074 \pm 0,010 \mathrm{Ab}$ & $0,038 \pm 0,005 \mathrm{Ba}$ & $0,056 \pm 0,007$ \\
\hline Média & $0,091 \pm 0,007$ & $0,037 \pm 0,004$ & - \\
\hline
\end{tabular}

${ }^{(1)}$ Médias \pm erro-padrão seguidas de letras iguais, minúsculas nas colunas e maiúsculas nas linhas, não diferem entre si pelo teste de Tukey, a 5\% de probabilidade.

Tabela 3. Número de folhas vivas por perfilho, em cinco cultivares de Urochloa spp., sob duas alturas de corte.

\begin{tabular}{|c|c|c|c|c|c|c|}
\hline Altura de corte & Arapoty & Basilisk & Capiporã & Marandu & Xaraés & Média \\
\hline $15 \mathrm{~cm}$ & $5,1 \pm 0,11 \mathrm{ABa}$ & $4,4 \pm 0,11 \mathrm{Cb}$ & $4,5 \pm 0,11 \mathrm{BCa}$ & $5,1 \pm 0,11 \mathrm{ABb}$ & $5,4 \pm 0,11 \mathrm{Aa}$ & $4,9 \pm 0,05$ \\
\hline $7,5 \mathrm{~cm}$ & $5,2 \pm 0,11 \mathrm{ABCa}$ & $5,1 \pm 0,11 \mathrm{BCa}$ & $4,8 \pm 0,11 \mathrm{Ca}$ & $5,7 \pm 0,11 \mathrm{Aa}$ & $5,4 \pm 0,11 \mathrm{ABa}$ & $5,3 \pm 0,05$ \\
\hline Média & $5,2 \pm 0,08$ & $4,7 \pm 0,08$ & $4,7 \pm 0,08$ & $5,4 \pm 0,08$ & $5,4 \pm 0,08$ & - \\
\hline
\end{tabular}


As alturas de corte também influenciaram o comprimento do colmo (CC), e os colmos das plantas cortadas a $15 \mathrm{~cm}$ do nível do solo foram cerca de $15 \%$ mais longos que os das plantas cortadas a 7,5 $\mathrm{cm}(10,1$ e $8,6 \mathrm{~cm}$, respectivamente). As plantas cortadas a $15 \mathrm{~cm}$ de altura apresentaram alturas finais de colmo menores que a linha de corte, enquanto as subparcelas cortadas a $7,5 \mathrm{~cm}$ apresentaram colmos que ultrapassaram a linha de corte e estiveram presentes em maior quantidade na composição do estrato colhido. No entanto, esse comprimento foi reduzido do verão para o inverno, para todos os genótipos (Tabela 4). Esse padrão de resposta pode ser atribuído às condições ambientais favoráveis ao crescimento da forragem no verão, cujo intervalo de 28 dias fixos entre cortes foi suficientemente extenso para promover o alongamento de colmos acima da linha de corte.

A altura de corte afetou também a densidade populacional de perfilhos (DPP), que é uma característica estrutural de grande importância para a persistência e produtividade de pastagens. Como os perfilhos individuais têm duração de vida limitada e variável, em consequência de fatores bióticos e abióticos, a população da pastagem é mantida por uma contínua reposição dos perfilhos mortos. O potencial de perfilhamento de uma determinada planta forrageira, em condições ambientais não limitantes, é determinado pelo número e atividade dos pontos de crescimento existentes (Pereira, 2009). Em pastos sob lotação intermitente, a intensidade de desfolhação é uma importante reguladora do ambiente luminoso das plantas (Portela et al., 2011). Conforme a severidade da desfolhação, as gemas basais são estimuladas pela luz, o que aumenta a população de perfilhos na pastagem. Nesse caso, a colheita da forragem à altura de 7,5 $\mathrm{cm}$ proporcionou maior DPP para a maioria das cultivares (Tabela 5). Apenas a 'Arapoty' apresentou redução no perfilhamento, com essa altura do resíduo, o que pode ser um sinal de que essa altura de corte pode estar fora dos limites de perenidade da forrageira o que reduziria a durabilidade da comunidade de plantas na pastagem, na falta de adubação ou deficiência hídrica.

Pastos colhidos a $7,5 \mathrm{~cm}$ sofreram perdas em torno de $20 \%$ de sua população original, enquanto pastos cortados a $15 \mathrm{~cm}$ perderam cerca de $10 \%$, quando

Tabela 4. Comprimento final de folhas expandidas e comprimento de colmos de cinco cultivares de Urochloa spp., no verão e inverno agrostológicos ${ }^{(1)}$.

\begin{tabular}{|c|c|c|c|c|c|c|}
\hline Estação & Arapoty & Basilisk & Capiporã & Marandu & Xaraés & Média \\
\hline & \multicolumn{6}{|c|}{ Comprimento final de folhas $(\mathrm{cm})$} \\
\hline Verão & $20,3 \pm 0,84 \mathrm{Ba}$ & $18,9 \pm 0,84 \mathrm{Ba}$ & $25,3 \pm 0,84 \mathrm{Aa}$ & $12,4 \pm 0,84 \mathrm{Da}$ & $16,4 \pm 0,84 \mathrm{Ca}$ & $18,6 \pm 0,37$ \\
\hline Inverno & $11,8 \pm 0,84 \mathrm{Bb}$ & $11,4 \pm 0,84 \mathrm{Bb}$ & $15,3 \pm 0,84 \mathrm{Ab}$ & $9,5 \pm 0,84 \mathrm{Cb}$ & $10,2 \pm 0,84 \mathrm{BCb}$ & $11,6 \pm 0,37$ \\
\hline \multirow[t]{2}{*}{ Média } & $16,0 \pm 0,59$ & $15,1 \pm 0,59$ & $20,3 \pm 0,59$ & $10,9 \pm 0,59$ & $13,3 \pm 0,59$ & - \\
\hline & \multicolumn{6}{|c|}{ Comprimento de colmos $(\mathrm{cm})$} \\
\hline Verão & $10,4 \pm 0,47 \mathrm{Ba}$ & $11,2 \pm 0,47 \mathrm{ABa}$ & $10,7 \pm 0,47 \mathrm{Ba}$ & $12,5 \pm 0,47 \mathrm{Aa}$ & $11,6 \pm 0,47 \mathrm{Aa}$ & $11,2 \pm 0,22$ \\
\hline Inverno & $7,2 \pm 0,47 \mathrm{Bb}$ & $7,1 \pm 0,47 \mathrm{Bb}$ & $6,5 \pm 0,47 \mathrm{Bb}$ & $8,4 \pm 0,47 \mathrm{Ab}$ & $8,1 \pm 0,47 \mathrm{Ab}$ & $7,4 \pm 0,22$ \\
\hline Média & $8,8 \pm 0,35$ & $9,2 \pm 0,35$ & $8,6 \pm 0,35$ & $10,5 \pm 0,35$ & $9,8 \pm 0,35$ & - \\
\hline
\end{tabular}

${ }^{(1)}$ Médias \pm erro-padrão seguidas de letras iguais, minúsculas nas colunas e maiúsculas nas linhas, não diferem pelo teste de Tukey, a $5 \%$ de probabilidade.

Tabela 5. Densidade populacional de perfilhos (perfilhos $\mathrm{m}^{-2}$ ) e relação senescência/crescimento de cinco cultivares de Urochloa spp., sob duas alturas de corte ${ }^{(1)}$.

\begin{tabular}{lcccccc}
\hline Altura de corte & Arapoty & Basilisk & Capiporã & Marandu & Xaraés & Média \\
\hline \multicolumn{7}{c}{} \\
$15 \mathrm{~cm}$ & $1.334 \pm 46 \mathrm{Aa}$ & $962 \pm 46 \mathrm{BCb}$ & $1.480 \pm 46 \mathrm{Ab}$ & $1.023 \pm 46 \mathrm{Bb}$ & $795 \pm 46 \mathrm{Cb}$ & $1.123 \pm 20,4$ \\
$7,5 \mathrm{~cm}$ & $1.195 \pm 46 \mathrm{Bb}$ & $1.126 \pm 46 \mathrm{Ba}$ & $1.620 \pm 46 \mathrm{Aa}$ & $1.190 \pm 46 \mathrm{Ba}$ & $1.005 \pm 46 \mathrm{Ba}$ & $1.227 \pm 20,4$ \\
\hline Média & $1.264 \pm 36,1$ & $1.044 \pm 36,1$ & $1.560 \pm 36,1$ & $1.107 \pm 36,1$ & $900 \pm 36,1$ & - \\
\hline \multicolumn{7}{c}{ Relação senescência/crescimento } \\
$15 \mathrm{~cm}$ & $0,033 \pm 0,008 \mathrm{ABa}$ & $0,095 \pm 0,024 \mathrm{ABa}$ & $0,020 \pm 0,004 \mathrm{Ba}$ & $0,110 \pm 0,012 \mathrm{Aa}$ & $0,121 \pm 0,020 \mathrm{Aa}$ & $0,076 \pm 0,007$ \\
$7,5 \mathrm{~cm}$ & $0,038 \pm 0,008 \mathrm{Aa}$ & $0,036 \pm 0,024 \mathrm{Aa}$ & $0,023 \pm 0,004 \mathrm{Aa}$ & $0,047 \pm 0,012 \mathrm{Ab}$ & $0,056 \pm 0,020 \mathrm{Ab}$ & $0,040 \pm 0,007$ \\
\hline Média & $0,036 \pm 0,006$ & $0,065 \pm 0,017$ & $0,021 \pm 0,004$ & $0,079 \pm 0,009$ & $0,088 \pm 0,014$ & - \\
\hline
\end{tabular}

${ }^{(1)}$ Médias \pm erro-padrão seguidas de letras iguais, minúsculas nas colunas e maiúsculas nas linhas, não diferem pelo teste de Tukey, a $5 \%$ de probabilidade. 
ambos completaram de 14 a 21 dias de rebrotação, o que mostra o efeito da altura de corte sobre a população de perfilhos, em diferentes períodos dentro de um ciclo de rebrotação (Tabela 6). Porém, a dinâmica de renovação dos perfilhos, em pastos baixos, promoveu a reestruturação da população no final do ciclo de rebrotação, que retornou à sua população original tanto no verão (28 dias) quanto no inverno (42 dias).

Aumentos na produção de forragem nem sempre representam elevada eficiência de colheita do material produzido. Em relação aos perfilhos individuais, embora a intensidade de desfolhação mais alta promova diminuição na DVF, houve maior expressão do efeito do manejo sobre os processos relacionados ao crescimento, expresso pelas maiores TALF. A maior resposta de crescimento, em relação à senescência nesses perfilhos, indica possíveis aumentos na eficiência de colheita, expressos pela menor relação senescência/crescimento ( $\mathrm{S} / \mathrm{C})$ e maiores valores de DPP, nos pastos que foram submetidos à desfolhação mais intensa. A relação $\mathrm{S} / \mathrm{C}$ sofreu efeito somente da interação altura x genótipo. Quando cortados a $15 \mathrm{~cm}$ de altura, as cultivares Basilisk, Marandu e Xaraés tiveram os maiores valores de relação S/C (Tabela 5). No entanto, as cultivares Arapoty e Capiporã, independentemente da altura de corte, tiveram menores valores de relação $\mathrm{S} / \mathrm{C}$, tendo sido consideradas cultivares promissoras, quando se almeja melhorar a eficiência de utilização da forragem produzida. Além disso, essa relação, combinada com a renovação de perfilhos, apoia a hipótese de que dosséis colhidos mais rentes ao solo são mais jovens e produtivos.

Tabela 6. Variação na população, no números de perfilhos e na média do número de perfilhos, durante o período de rebrotação, comparada à população original (início da rebrotação), em pastos de Urochloa spp. sob duas alturas de corte.

\begin{tabular}{|c|c|c|c|}
\hline $\begin{array}{l}\text { Altura } \\
\text { de corte }\end{array}$ & População $^{(1)}$ & Número de perfilhos $\mathrm{m}^{-2}$ & $\begin{array}{l}\text { Média do número } \\
\text { de perfilhos } \mathrm{m}^{-2}\end{array}$ \\
\hline \multicolumn{4}{|c|}{ Período de rebrotação intermediário } \\
\hline $15 \mathrm{~cm}$ & $-9 \%$ & $70-139^{(2)}$ & -104 \\
\hline $7,5 \mathrm{~cm}$ & $-19 \%$ & $172-324$ & -228 \\
\hline \multicolumn{4}{|c|}{ Período de rebrotação final } \\
\hline $15 \mathrm{~cm}$ & $-2 \%$ & $16-31$ & -23 \\
\hline $7,5 \mathrm{~cm}$ & $+5 \%$ & $45-85$ & +60 \\
\hline
\end{tabular}

(1)Valores negativos representam redução na população original (início da rebrotação), valores positivos representam aumento na população original (início da rebrotação). ${ }^{(2)}$ Variação máxima e mínima obtidas entre as cinco cultivares.

\section{Conclusões}

1. Dosséis cortados a 7,5 e a $15 \mathrm{~cm}$ do solo permanecem dentro de níveis de perenidade que garantem rebrotação satisfatória nas condições edafoclimáticas a que os genótipos foram expostos.

2. Por suas características morfogênicas e estruturais, as cultivares Xaraés e Capiporã são as mais produtivas.

3. O uso de resíduos mais baixos acelera a renovação dos perfilhos e aumenta a utilização da forragem produzida.

\section{Referências}

ALEXANDRINO, E.; NASCIMENTO JUNIOR, D. do; MOSQUIM, P.R.; REGAZZI, A.J.; ROCHA, F.C. Características morfogênicas e estruturais na rebrotação da Brachiaria brizantha cv. Marandu submetida a três doses de nitrogênio. Revista Brasileira de Zootecnia, v.33, p.1372-1379, 2004.

BARBOSA, R.A.; NASCIMENTO JUNIOR, D. do; EUCLIDES, V.P.B.; REGAZZI, A.J.; FONSECA, D.M. da. Características morfogênicas e acúmulo de forragem do capim-Tanzânia (Panicum maximum Jacq. cv. Tanzânia) em dois resíduos forrageiros pós-pastejo. Revista Brasileira de Zootecnia, v.31, p.583-593, 2002.

CASAGRANDE, D.R.; RUGGIERI, A.C.; JANUSCKIEWICZ, E.R.; GOMIDE, J.A.; REIS, R.A.; VALENTE, A.L. da S. Características morfogênicas e estruturais do capim-marandu manejado sob pastejo intermitente com diferentes ofertas de forragem. Revista Brasileira de Zootecnia, v.39, p.2108-2115, 2010 .

DAVIES, A. Leaf tissue remaining after cutting and regrowth in perennial ryegrass. Journal of Agricultural Science, v.82, p.165-172, 1974.

DURU, M.; DUCROCQ, H. Growth and senescence of the successive leaves on a cocksfoot tiller. Effect of nitrogen and cutting regime. Annals of Botany, v.85, p.645-653, 2000.

GOMIDE, C.A.M.; GOMIDE, J.A.; PACIULLO, D.S.C. Morfogênese como ferramenta para o manejo de pastagens. Revista Brasileira de Zootecnia, v.35, p.554-579, 2006.

LEMAIRE, G.; AGNUSDEI, M. Leaf tissue turnover and efficiency of herbage utilization. In: LEMAIRE, G.; HODGSON, J.; MORAES, A. de; NABINGER, C.; CARVALHO, P.C. de F. (Ed.). Grassland ecophysiology and grazing ecology. Wallingford: CAB International, 2000. p.265-288.

LEMAIRE, G.; CHAPMAN, D. Tissue fluxes in grazing plant communities. In: HODGSON, J.; ILLIUS, A.W. (Ed.). The ecology and management of grazing systems. Wallingford: $\mathrm{CAB}$ International, 1996. p.3-36.

LITTELL, R.C.; MILLIKEN, G.A.; STROUP, W.W.; WOLFINGER, R.D.; SCHABENBERGER, O. SAS for mixed models. $2^{\text {nd }}$ ed. Cary: SAS Institute, 2006. 813p. 
MARTUSCELLO, J.A.; FONSECA, D.M. da; NASCIMENTO JÚNIOR, D. do; SANTOS, P.M.; RIBEIRO JUNIOR, J.I.; CUNHA, D. de N.F.V. da; MOREIRA, L. de M. Características morfogênicas e estruturais do capim-xaraés submetido à adubação nitrogenada e desfolhação. Revista Brasileira de Zootecnia, v.34, p.1475-1482, 2005.

NAVAS, M.-L.; DUCOUT, B.; ROUMET, C.; RICHARTE, J.; GARNIER, J.; GARNIER, E. Leaf life span, dynamics and construction cost of species from Mediterranean old-fields differing in successional status. New Phytologist, v.159, p.213-228, 2003.

PACIULLO, D.S.C.; DERESZ, F.; AROEIRA, L.J.M.; MORENZ, M.J.F; VERNEQUE, R. da S. Morfogênese e acúmulo de biomassa foliar em pastagem de capim-elefante avaliada em diferentes épocas do ano. Pesquisa Agropecuária Brasileira, v.38, p.881-887, 2003.

PEDREIRA, B.C. e; PEDREIRA, C.G.S.; SILVA, S.C. da. Estrutura do dossel e acúmulo de forragem de Brachiaria brizantha cultivar Xaraés em resposta a estratégias de pastejo. Pesquisa Agropecuária Brasileira, v.42, p.281-287, 2007.

PEREIRA, L.E.T. Morfogênese e estrutura do dossel de pastos de capim-marandu submetidos a lotação contínua e ritmos morfogênicos contrastantes. 2009. 111p. Dissertação (Mestrado) - Escola Superior de Agricultura Luiz de Queiroz, Piracicaba.

PORTELA, J.N.; PEDREIRA, C.G.S.; BRAGA, G.J. Demografia e densidade de perfilhos de capim-braquiária sob pastejo em lotação intermitente. Pesquisa Agropecuária Brasileira, v.46, p.315-322, 2011.
REZENDE, C. de P.; PEREIRA, J.M.; PINTO, J.C.; MUNIZ, J.A.; BORGES, A.M.F.; ANDRADE, I.F. de; EVANGELISTA, A.R. Dinâmica de perfilhamento e fluxo de biomassa em capim-cameroon sob lotação rotativa. Revista Brasileira de Zootecnia, v.37, p.1750-1757, 2008.

SANTOS, H.G. dos; JACOMINE, P.K.T.; ANJOS, L.H.C. dos; OLIVEIRA, V.A. de; OLIVEIRA, J.B. de; COELHO, M.R.; LUMBRERAS, J.F.; CUNHA, T.J.F. (Ed.). Sistema brasileiro de classificação de solos. 2.ed. Rio de Janeiro: Embrapa Solos, 2006. 306p.

SANTOS, M.E.R.; FONSECA, D.M. da; BRAZ, T.G. dos S.; SILVA, S.P. da; GOMES, V.M.; SILVA, G.P. Características morfogênicas e estruturais de perfilhos de capim-braquiária em locais do pasto com alturas variáveis. Revista Brasileria de Zootecnia, v.40, p.535-542, 2011.

SAS INSTITUTE. SAS/STAT user's guide. Version 7.1. Cary: SAS Institute, 2001.

SBRISSIA, A.F.; SILVA, S.C. da. Compensação tamanho/ densidade populacional de perfilhos em pastos de capim-marandu. Revista Brasileira de Zootecnia, v.37, p.35-47, 2008.

SILVA, S.C. da; NASCIMENTO JÚNIOR, D. do. Avanços na pesquisa com plantas forrageiras tropicais em pastagens: características morfofisiológicas e manejo do pastejo. Revista Brasileira de Zootecnia, v.36, p.121-138, 2007. Suplemento especial.

SUPLICK, M.R.; READ, J.C.; MATUSON, M.A.; JOHNSON, J.P. Switchgrass leaf appearance and lamina extension rates in response to fertilizer nitrogen. Journal of Plant Nutrition, v.25, p.2115-2127, 2002.

$\overline{\text { Recebido em } 14 \text { de fevereiro de } 2011 \text { e aprovado em } 26 \text { de maio de } 2011}$ 